\title{
Desinformação e fake news: health literacy no enfrentamento da pandemia da COVID-19
}

\author{
Misinformation and fake news: health literacy to fight against the COVID-19 \\ pandemic
}

\author{
Michele Nacif Antunes ${ }^{1}$ \\ Taísa Sabrina Silva Pereira ${ }^{2}$ \\ Paola Pinheiro Bernardi Primo ${ }^{1}$ \\ Adauto Emmerich Oliveira ${ }^{1}$
}

${ }^{1}$ Universidade Federal do Espírito Santo. Vitória/ES, Brasil.

${ }^{2}$ Universidad de las Américas Puebla. San Andrés Cholula/PUE, México.

\begin{abstract}
Nas grandes inundações, o primeiro recurso que fica escasso é a água potável. Da mesma forma, nas inundações de informação, quando os sinais chegam de todos os lugares, por meio da internet e de qualquer lugar do mundo, o mais difícil é identificar a informação "potável” diante de várias fontes de informação "tóxicas"1. Assim, a localização dessas fontes potáveis de informação cada vez mais ocupa um lugar de centralidade nos processos de comunicação e informação na sociedade contemporânea e assume extrema importância, especialmente diante da pandemia da COVID-19.
\end{abstract}

No mundo, foram registrados até 19 de novembro de 2020, 55.928.327 de casos da doença e 1.344.003 mortes². E no Brasil, no mesmo período, o número de casos confirmados é de 5.945 .849 e 167.455 mortes, ocupando o terceiro lugar de países com mais casos acumulados, sendo Estados Unidos e India, o primeiro e segundo lugar respectivamente. Do total de casos do Brasil, 175.172 casos e 4.080 óbitos foram registrados no Espírito Santo ${ }^{3}$.

Com o elevado e crescente número de casos, a Organização Mundial de Saúde (OMS) ${ }^{4}$ alertou que o surto e a resposta ao coronavírus foram acompanhados por uma enorme "infodemia" - uma abundância excessiva de informação algumas precisas e outras não - que dificultam o acesso a fontes confiáveis para orientar a ação. Nesse cenário, há também uma "desinfodemia", que pode ser definida como a propagação de uma enfermidade facilitada pela desinformação viral que viaja na velocidade de uma postagem do twitter, por exemplo ${ }^{5}$. Assim, uma epidemia global de desinformação - que se espalha rapidamente pelas plataformas de mídia social e outros meios de comunicação - torna-se um sério problema para a saúde pública.

Estudos recentes sobre a pandemia da COVID-19 apontam que o fornecimento de informação falsa ou incorreta nos estágios iniciais de uma pandemia pode ter importantes consequências de como uma doença afeta a população, e ainda interromper a iniciativa do governo que visa conter a epidemia e potencialmente aumentar o risco de contágio ${ }^{6}$. 
No Brasil, o Ministério da Saúde disponibilizou um espaço exclusivo para a população enviar informação viral, que são apuradas pelas áreas técnicas e respondidas oficialmente se são verdade ou mentira ${ }^{7}$.

A preocupação com a pandemia da COVID-19 diante da circulação de notícias falsas, de desinformação ou informação incorreta é global. Lazer et al. ${ }^{8}$ definem "notícias falsas" como informação fabricada que imita o conteúdo da mídia na forma, mas não no processo organizacional ou intenção, pois carecem das normas e processos editoriais para garantir a precisão e credibilidade da informação. As notícias falsas se sobrepõem a outros distúrbios da informação, como a disseminação de informação incorreta (informações falsas ou enganosas) e desinformação (informações falsas que são propositalmente difundidas para enganar as pessoas) $)^{9}$.

Assim estamos diante de um importante desafio: imensa quantidade de informação acessível que pode alterar a maneira como a informação é consumida, afetando a ação, tanto de maneira positiva quanto negativa.

Krishna e Thompson ${ }^{10}$ advogam que no centro da discussão sobre desinformação relacionada à saúde está a noção de health literacy (literacia em saúde), definida por Parker, Ratzan e Lurie ${ }^{11}$ como a capacidade para obter, processar e entender a informação e serviços básicos de saúde necessários para tomar as decisões de saúde apropriadas. Nesse sentido, a desinformação não é meramente mensagens falsas e imprecisas, ela se constitui como tal quando o destinatário julgar a informação errada útil na busca de informação para a solução de algum problema. A desinformação, portanto, impediria a obtenção da literacia em saúde entre indivíduos, pois aqueles com a informação incorreta podem não estar adequadamente equipados para tomar decisões de saúde apropriadas.

Nessa direção, Zaracosta ${ }^{12}$ alerta que o rápido desenvolvimento da COVID-19 em uma pandemia exigiu que as pessoas adquirissem e aplicassem informação sobre saúde e adaptassem seu comportamento em ritmo acelerado. De acordo com Paakkari e $\mathrm{Okan}^{13}$, a atual pandemia destacou aspectos importantes: globalmente, health literacy é tão importante para a prevenção de doenças transmissíveis quanto é para doenças não transmissíveis. Além disso, juntamente com a preparação do sistema de saúde, a preparação individual é essencial para resolver problemas complexos da vida real. Para os autores, o desenvolvimento de health literacy é ainda mais atual do que nunca para preparar os indivíduos para situações que exigem reação rápida.

Embora o termo infodemiologia tenha sido cunhado em 2002 por Gunther Eysenbach ${ }^{14}$, as preocupações com infodemias ou surtos de desinformação são quase tão antigas quanto a própria World Wide Web. Como um dos pioneiros no estudo da infodemia, Eysenbach ${ }^{15}$ postulou quatro pilares do manejo infodêmico no contexto da COVID-19: 1) monitoramento da informação (infovigilância); (2) construir capacidade de Health Literacy e science literacy; (3) encorajar o refinamento do conhecimento e os processos de melhoria da qualidade da informação, como verificação de fatos e revisão por pares; e (4) tradução de conhecimento precisa e oportuna, minimizando fatores de distorção, como influências políticas ou comerciais.

Nessa direção, durante uma pandemia, emergência ou crise pode-se considerar que a comunicação de risco também assume um papel de extrema importância. Powell e Leiss ${ }^{16}$ afirmam que os problemas da comunicação de temas que envolvem o risco originam-se nas diferenças marcantes entre a linguagem científica e a linguagem do público.

De um lado, estão os "especialistas", comunidade científica e atores governamentais referindo-se usualmente à literatura científica e usando terminologia técnica, como a epidemiologia ou estatística. Do outro lado, está a "avaliação pública", quando as pessoas se referem a questões de risco em sua linguagem comum e no contexto das próprias experiências cotidianas, sem necessariamente recorrerem aos resultados do conhecimento especializado. Dessa forma, a prática da boa comunicação sobre os riscos ocorre na zona que separa as duas linguagens e traduz as descobertas científicas e as avaliações de riscos probabilísticos em termos compreensíveis, além de explicar os graus de incerteza, as lacunas no conhecimento e os projetos de pesquisa em andamento.

Em todas as situações de riscos nas quais se exigem respostas por parte das políticas públicas, uma das consequências mais sérias é o surgimento de uma lacuna nas informações sobre os riscos. Isso ocorre, por exemplo, quando as informações científicas são fornecidas de forma parcial e ocasional e são interpretadas de formas aparentemente 
conflitantes $^{16}$. E, consequentemente, essa lacuna é preenchida por outras fontes, que toma para si o desafio e preenche o vácuo com a própria informação ou desinformação.

E essa proliferação de vozes dissonantes parece gerar um certo ceticismo científico. De acordo com VasconcellosSilva e Castiel $^{17}$, em condições ideais de comunicação pública, as autoridades deveriam alinhar-se a um regime total de transparência da informação e de compreensão facilitada para gerar credibilidade, confiança e parceria com as mídias. Os autores complementam que nos hiatos de versões aceitáveis e em meio a indeterminações, os indivíduos tornam-se experts de si mesmos, consumindo desinformação, fake news e reproduzindo narrativas de risco falaciosas com consequências desastrosas.

Diante de tais desafios, o limite entre o excesso de informação e desinformação torna-se muito tênue. Assim, é essencial investir também em estratégias que possibilitem à sociedade aprimorar sua capacidade para obter, processar e usar a informação para melhor orientar a ação.

A health literacy é uma estratégia reconhecida internacionalmente como fundamental para compor o rol de iniciativas públicas para o enfrentamento das doenças transmissíveis, particularmente quando orientada para alcançar os mais vulneráveis, colocando-se como promotora de equidade em saúde. E é cada vez mais necessária no contexto da pandemia da COVID-19.

\section{REFERENCIAS|}

1. Carré H. A mídia na era da pós-verdade. [CD-ROM]. Espanha; 2017.

2. World Health Organization. [Internet]. WHO Coronavirus Disease (COVID-19) Dashboard Data last updated: 2020/11/24, 10:43am CET Overview. Data Table. Acesso em 20 de novembro de 2020. Disponível em: https:/ / covid19. who.int/.

3. Brasil. [Internet]. Painel Coronavírus (COVID-19). [Acesso 20 de noviembre de 2020]. Disponível em: https://covid. saude.gov.br/.

4. World Health Organization. Novel Coronavirus (2019-nCoV) Situation Report-13. 2020. [Acesso em 22 de março de 2021]. Disponível em https://www.who.int/docs/default-source/coronaviruse/situationreports/20200202-sitrep-13ncov-v3.pdf.

5. Nogués G. Desinfodemia, la otra epidemia. [internet]. Adox, Desarrollando Información. Disponível em: http://adox. com.ar/desinfodemia-la-otraepidemia/. Acesso em: 22/04/2020.

6. Cinelli M, Quattrociocchi W, Galeazzi A, Valensise CM, Brugnoli E, Schmidt AL, et al. The COVID-19 Sci Rep. 2020; 10(1):16598.

7. Posenato GL, Duarte E. Infodemia: excesso de quantidade em detrimento da qualidade das informações sobre a COVID-19. Epidemiol. Serv. Saúde. 2020; 29(4): e2020186.

8. Lazer DMJ, Baum MA, Benkler Y, Berinsky AJ, Greenhill KM, Menczer F, et al. The science of fake news: Addressing fake news requires a multidisciplinary effort. Science. 2018; 359(6380):1094-1096.

9. Bakir V, Mcstay A. Fake News and The Economy of Emotions: Problems, causes, solutions. Digital Journalism. 2018; 6(2):154-175.

10. Krishna A, Thompson TL. Misinformation about Health: A Review of Health Communication and Misinformation Scholarship. American Behavioral Scientist. 2019; 65(2): 316-332. 
11. Parker RM, Ratzan SC, Lurie N. Health literacy: A policy challenge for advancing high-quality health care. Health Aff. 2003; 22(4):147-53.

12. Zaracosta J. How to fight an infodemic. Lancet. 2020; 395(10225): 676,

13. Paakkari L, Okan O. COVID-19: health literacy is an underestimated problem. Lancet Public Health. 2020; 5(5): e249-e250.

14. Eysenbach G. Infodemiology: the epidemiology of (mis)information. Am J Med. 2002; 113(9),763-765.

15. Eysenbach G. How to Fight an Infodemic: The Four Pillars of Infodemic Management. J Med Internet Res. 2020;22(6):e21820.

16. Powell D, Leiss W. Um diagnóstico das falhas de comunicação sobre riscos. In: Massarani L, Moreira IC. Terra Incógnita. A interface entre ciência e público. Rio de Janeiro: Casa da Ciência; Editora Fiocruz; 2005. p. 183-202.

17. Vasconcellos-Silva PR, Castiel LD. COVID-19, fake news, and the sleep of communicative reason producing monsters: the narrative of risks and the risks of narratives. Cad. Saúde Pública. 2020; 36(7): e00101920. 